\title{
Populism and Media in Germany: How different newspapers report about the AfD
}

\author{
Jannik Lenz ${ }^{1}$
}

\begin{abstract}
It has generally been established that the media has an effect on populism and can either help or hinder it. However, there is a lack of research on how populist parties are portrayed in the media. In this paper, I investigate four German newspapers and the way in which they cover the German populist party "Alternative für Deutschland". The German case is special, as the past German experiences with right-wing radicalism, have led the media in Germany to develop fear of contact or "Berührungsangst" with populism. By conducting a qualitative discourse analysis, I find that all newspapers try to contain the AfD and show signs of "Berührungsangst". However, it becomes clear that the traditional categories, established through quantitative content analyses, are inadequate to accurately cover all possible responses of the newspapers. Thus, I argue that more qualitative discourse analyses are needed in this field, in order to establish more nuanced categories, upon which future quantitative and qualitative research can build.
\end{abstract}

\section{Introduction}

Populism has spread across Europe in a wave, challenging the traditional parties with new and often radical ideas. Despite generally being an advocate of European integration, Germany has not been spared from this development of Euroscepticism and populism. While a lack of media attention has hindered populism from becoming mainstream in Germany in the past (Wielenga \& Hartlieb, 2011, p.31), this has changed in recent years. The party "Alternative für Deutschland" (Alternative for Germany or AfD) was founded in 2013 and has obtained increasingly high elections results. This seems to suggest that the German media have changed their approach to populism. Therefore, this paper answers the question: How is the AfD represented by the "Aachener Nachrichten" and "BILD.de" from West Germany, compared to the "Mitteldeutsche Zeitung" and the "B.Z." from East Germany? As the AfD is especially successful in the East of Germany, I try to determine if there is a difference in how Western and Eastern newspapers portray populism. I investigate the extent to which the different newspapers can be categorized as pursuing containment or collaboration. Furthermore, I investigate to what extent the newspapers show signs of "Berührungsangst" (fear of contact and connection), as established by Decker (2004, p.261).

Populism has become a significant influence in politics today and it is therefore very important to understand what it is and how it works. An increasing number of scholars have started to focus on the significance of the media as a platform of visibility for populism.

\footnotetext{
1 Jannik Lenz received a bachelor degree in European Studies at Maastricht University in 2019. At the moment he takes a Research Master in European Studies at Maastricht University. Contact: janniklenz97@gmail.com
} 
However, research that investigates how newspapers report on populism is often conducted through quantitative content analyses, which draw general conclusions. In this paper, I conduct a qualitative, discourse analysis, in order to gain a more in-depth understanding of the newspaper articles I analyse. This enables me to improve upon the established categories of newspaper reactions to populism.

I start by developing a suitable definition of populism for this paper and argue that the AfD is a right-wing populist party, according to this definition. I then discuss the existing literature on media and populism, especially work that has focused on Germany. Furthermore, I demonstrate the relevance of Germany as a case study and I explain how the specific newspapers and newspaper articles were chosen. I continue to develop a theoretical framework, which combines traditional categories of newspaper reactions with categories of "Berührungsangst". Moreover, I explain why I chose to conduct a qualitative discourse analysis over a quantitative content analysis and how I analysed the newspaper articles. I then present the findings of this discourse analysis. Finally, I argue that all newspapers fit into the category of "containment" to some extent and also show signs of "Berührungsangst". However, I also demonstrate that more nuanced categories, and a detailed scale within each category, are necessary to categorise the newspapers more accurately.

\section{What is populism and is the AfD a populist party?}

There has been much debate over an exact definition of populism, one that entails its various strands and that is neither too narrow, nor too general to be of use. I do not try to come up with a new definition of populism or one that is applicable in every case. What I do set out to do, is to define populism in a way that is relevant for the analysis of the newspaper coverage of the AfD in Germany. When trying to define populism, one cannot help but come across the work of Mudde. He identified the division of society into a corrupt elite and the common people, as an integral part of nearly all forms of populism (2004, p.543). Furthermore, he believes that populism is a form of nativism, which wants the state to be inhabited by natives and sees non-native elements as a threat (2007, p.19). In this paper, I adopt a definition of populism based on these criteria. Canovan adds that a crucial feature of populism is its promise of redemption (1999, p.14). Da Silva and Vieira expand on this by arguing that populism promises redemption from feelings of ressentiment and that the redemptive side of populism needs to be kept in mind when studying it (2018, p.19). Therefore, this paper will add the redemptive feature of populism to the traditional definition of Mudde. To sum it up: Populist parties make a clear distinction between elites and common people, see non-native elements as a threat and promise redemption from feelings of ressentiment. This definition demonstrates the core beliefs and promises of a populist party. Therefore, it enables me to establish, whether or not the AfD is a populist party.

Indeed, according to this definition, the AfD should be classified as a populist party. The party itself claims that it is not populist (Franzmann, 2016, p.461). However, Franzmann found that it did use populist discourse extensively in 2013 (2016, p.476). Nevertheless, he also argues that this was only a temporary, tactical agenda and that the degree of populism in the AfD varies over time $(2016, p .476)$. It is important to note, that Franzmann's research only covers the initial formation period of the party, which lasted up until the European Parliament election in 2014 (2016, p.462). The AfD has become significantly more populist since then. Ceyhan argues that the AfD distinguishes between elites and common people and sees non-native elements, especially Muslims, as a threat (2016, pp.52-58). Therefore, the AfD demonstrates several of the signs of a populist party, established before. 
Unfortunately, none of these authors have investigated, whether the AfD promises redemption from feelings of ressentiment. However, it does seem that the AfD specifically targets areas of German resentment. For example, Franzmann argues that the AfD was initially focused on the Euro Crisis, because it was a highly discussed topic in the media, which many Germans felt strongly about (2016, p.473). Thus, it seems that they are focusing on topics that produce feelings of ressentiment. By promising to solve the problems in those areas, they also promise to redeem people from their feelings of ressentiment. The AfD is certainly a populist party according to the criteria of Mudde. They also show some evidence of promising redemption from feelings of ressentiment.

It is important to note that the AfD is not only a populist party according to the criteria of this paper, but that the analysed newspapers also see the AfD as populist. While this may not be as academically relevant, it is essential to my research. If the newspapers would not view the AfD as populist, I could not investigate how they react to populism. Whether the party is indeed populist or not, is therefore less important than whether or not the newspapers perceive it as such. Each newspaper published several articles, which label the AfD as a populist party (e.g. Aa17, Aa24, Aa31, Bi1, Bi2, Bi9, $B z 2, B z 3, B z 7, M i 1, M i 8, M i 25)$. This is a common feature of all the newspapers, and none of them published an article debating whether the AfD is populist. Therefore, the newspapers also view the AfD as populist.

\section{The state of the academic debate on populism and the media in Germany}

A lot of work has already been done to develop several different factors that explain the rise of the AfD in Germany. Kadlot and Boros mention that the dominant political themes in Europe have shifted to their advantage (2016, p.22). Wielenga and Hartlieb fear that the weakness of the established parties leads to the success of populism (2011, p.26). Similarly, according to Rösel and Samartzidis, a lack of trust in the government is a major factor for the success of populism in Eastern Germany (2018, p.13). They also point out that a lack of tolerance has a similar effect and that overall, Western Germany demonstrates higher levels of trust and tolerance (p.13). However, the role of the media in this development has hardly been discussed, even though, according to Wielenga and Hartlieb, the media used to play a significant role in preventing populism from gaining visibility and popularity in Germany (2011, p.31). Therefore, this paper attempts to fill this gap in the literature by looking into the relation of the media and the rise of the AfD and into how media from East and West views and reports on populism in Germany.

There are many authors that argue that there is a connection between the success of populism and the way that it is represented in the media. Mazzeloni argues that the rise of populism was in part made possible by their effective use of the media and that tabloid media often frame and support charismatic, populist leaders as underdogs (2008, pp.50-52). Norstedt elaborates that the media can create fear in the population, which will be exploited by populists (2013, p.317). Other authors have also focused on how the media create a favourable situation for populism. According to Freedman, the structural conditions of the media make the coverage of populism more profitable, and therefore more frequent (2018, p.606). Finally, Gerbaudo has investigated the connection between social media and populism and found that there is an affinity between the two, as populists use social media as a platform against elites (2018, p.746). This demonstrates that the media can play a significant role in the success of populism. Therefore, in this paper, I investigate how the German media report on the AfD, as it adds 
to our understanding of how the media affect the rise of populism. My findings challenge some of the predictions of the current literature, such as the expectation that tabloid media generally support populism.

Some authors doubt that the media play a large role in the success of populism. Postill, for istance, reminds us that non-populist politicians have also used social media effectively in the past (2018. p.761). Furthermore, Deacon and Wright claim that the media did not help the UK Independence Party (Ukip) and that coverage of the party only increased after it had already become a significant factor in politics (2016, p.180). Finally, Manucci and Weber conducted an empirical study, which was unable to find an increase in populist discourse in newspapers in Europe (2017, p.329). These authors demonstrate that the media are only one of many factors that determine the success of populism. Nonetheless, it is a significant factor. The method applied by Manucci and Weber was only focused on identifying the use of populist discourse by the media (p.320) and therefore did not detect whether there was an increase in reports on populist parties. A previous study, conducted by Roodjuin found that the political debates in newspapers in Europe had indeed become more populist between 1990 and 2005 (2014, p.740). Furthermore, Burack and Snyder-Hall found that in America, the mass media actively support populism and that while the democrats are generally more skilled at using social media, the conservative media still use it as an extension of traditional media (2012, pp. 449-450). These authors demonstrate that in many situations, the media were crucial to explain populist success. In the case of Germany, the lack of attention by the media was even identified as a reason for the unpopularity of populism (Wielenga \& Hartlieb, 2011, p.31). Therefore, there is a connection between the media and the success of populism in Germany. However, only by conducting an in-depth analysis on how the newspapers report about the AfD, is it possible to determine how significant this connection is.

\section{Selection of country, newspaper and articles}

Germany is a particularly good case to investigate how the media report on populism because of its uniqueness. It was one of the European countries in which populism took the longest to take root, as the AfD was only founded in 2013. Furthermore, as Decker argues, the German media had "Berührungsangst" with populism and therefore they were a factor that prevented populism from becoming successful (2004, p.261). Thus, Germany provides me with a unique opportunity to investigate how and why the media's perception of populism changed. In 2011, when Wielenga and Hartlieb published their research, they also reported that the newspapers hardly covered populism at all (p.31). However, when Manucci and Weber conducted their analysis in 2013, they were able to include German newspapers in their analysis (p.325). I myself had no trouble finding articles from 2017, discussing the AfD. Therefore, the success of the AfD, after it was established in 2013, was accompanied by a shift in the willingness of the German media to talk about populism. This demonstrates that there is some sort of connection between the media and the populist AfD.

I chose to focus my analysis on newspaper articles. Newspapers are still the most relevant and consistent form of traditional media. While other forms of media, such as television, are becoming more relevant, they are generally not as consistent in how and on what they report. Furthermore, Alvares \& Dahlgreen have found that television journalism generally behaves and reports similarly to tabloids (2016, p.53). Finally, there seems to be some ambiguity, whether the social media system is nearly as relevant to populist success. According to Postill, social media is used successfully by many politicians,

\footnotetext{
4 \begin{tabular}{l|l} 
Marble \\
Research \\
Papers
\end{tabular}
} 
not just populists (2018, p.761). Burack and Snyder-Hall even argue that, in America, the democrats are generally more successful at using social media than the conservatives and populists (p.450). Therefore, I have decided not to include texts from social media in my research. Not only would their relevance be questionable, but they would also require a different approach and method to analyse.

The four newspapers I investigate were chosen on the basis of providing a large and relevant spectrum that enables the investigation of the reaction of the media. As Mazzeloni argues, there is a difference in the way that elite newspapers and tabloid newspapers report on populism, as tabloid newspapers generally report on it more positively (2008, p.52). Other authors, such as Manucci and Weber, have also made sure to investigate both tabloid and elite newspapers (2017, p.319). Therefore, I have chosen two tabloid and two elite newspapers from Germany. Furthermore, as I am analysing the success of populism in Germany, it is important to note that the AfD is generally more successful in elections in Eastern Germany than in Western Germany. I argue that it is necessary to investigate how the newspapers represent this difference in voting behaviour. Thus, I chose two newspapers from Eastern Germany and two from Western Germany. From the East, I chose to analyse the quality newspaper "Mitteldeutsche Zeitung", and the tabloid "B.Z." (Berliner Zeitung). The "Mitteldeutsche Zeitung" comes from Sachsen Anhalt, which is the region that saw the most votes for the AFD in the most recent elections. The "B.Z." comes from Berlin. While I would have ideally preferred a tabloid from Sachsen Anhalt, there are only three tabloids in Eastern Germany, none are from Sachsen Anhalt. As Berlin has shown significant support for the AfD as well, the "B.Z." was chosen as the tabloid from the East. Furthermore, I chose to analyse the online tabloid "BILD.de" and the quality newspaper "Aachener Nachrichten". The "Aachener Nachrichten" comes from the city of Aachen in Western Germany, which saw low levels of support for the AfD. Overall, this selection allows me to compare and contrast very different newspapers, such as print and online tabloids, as well as quality newspapers. Furthermore, the newspapers come from different regions that differ in size. This ranges from the "Aachener Nachrichten", which is distributed in a single city, to "BILD.de" which can be read in all of Germany. The regions that the newspapers come from also differ in the amount of support that they gave the AfD. This ensures that the newspapers are very different and are published under different circumstances. Therefore, they provide a high likelihood of having different reactions to the AfD. While this selection cannot claim to be representative of newspapers in Germany overall, it is as representative as it can be, consisting of four newspapers.

The articles of the newspapers were all chosen from the same, specific time period. Stewart et al. divide media responses to populism into four phases: a ground-laying, an insurgent, an established and a declining phase (2003, p.225). My focus will be on the established phase, in which the party starts to see electoral results, as this phase generally sees the highest coverage of populism by the media. Moreover, this allows me to obtain the most current results, as the good election results by the AfD suggest that German populism is currently in the established phase. I chose the exact time period to be from the 24th August 2017 to the 24th October 2017, as the latest German elections took place on September 24, 2017. Therefore, this timeframe includes newspaper articles from one month before and one month after the election. Other scholars have also chosen to investigate articles from one month before elections, as most articles on populism are generally published during this time (Manucci \& Weber, 2017, p.319). I chose to also include the month after the election, as I am conducting qualitative research and therefore interested in the reaction of the newspapers to the election success of the AfD. 
Finally, I only analysed articles that include some sort of opinion on or value-laden statement about the AfD. I only included articles that fulfilled this criterion because these articles demonstrate the position that a newspaper takes towards the AfD. While all of the newspapers published neutral articles on the AfD, these articles do not allow for an in-depth analysis of the reaction of the newspaper to the AfD. As all of the newspapers also published articles on the AfD that express an opinion on the party, I chose to focus on those articles and exclude the ones that report on it in a neutral fashion. In the end, I analysed a total of 97 articles, 33 from the "Aachener Nachrichten", 30 from the "Mitteldeustche Zeitung", 25 from the "B.Z." and 9 from "BILD.de". Notably, "BILD.de" published far fewer articles that fit the selection than the other newspapers, as most of its articles reported on the AfD in a neutral way. This is taken into account in the analysis.

\section{Categorizing media responses to populism}

In order to analyse the newspapers, I need to categorize their response to populism. For this purpose, I draw greatly on the work done by Deacon and Wright (2016). As they do, I will use Krämer's division of media responses into "collaboration" and "containment" (2014, p.57). Krämer also developed another category, "competition", in which the newspapers do not report on populist parties or leaders, but on populist issues, thus becoming populist themselves (p.57). However, I ignore articles from this category, as I am interested in their reaction to the populist AfD, rather than whether they are populist themselves or not. Deacon and Wright further make a distinction between "passive containment", where the newspapers mostly ignore populism, and "active containment", where the newspapers report on populism in a negative way (2016, p.170). While this distinction does make sense for quantitative research, I will only focus on active containment, as my qualitative approach does not allow me to judge how much coverage populism receives from a newspaper. Thus, if I mention containment, it should always be understood as active containment. Categorizing the reactions of newspapers to populism in this way allows me to compare if the newspapers from the West have different reactions than the newspapers from the East and whether there is a difference between elite and tabloid newspapers.

The concept of "Berührungsangst" also plays a key role in my analysis of the newspaper articles. In his book from 2004, Decker argues that the media have a certain "Berührungsangst" (fear of contact) with populism, as it is often associated with National Socialism, and that this prevents populism from taking root in Germany (p.261). Recently, the AfD has become much more successful in elections, especially in Eastern Germany and the news report about it regularly. Therefore, I analyse whether "Berührungsangst" is still present in today's newspapers and if it differs in Western and Eastern media. In order to achieve this, I further categorise newspapers into displaying "no Berührungsangst", "some Berührungsangst" and "strong Berührungsangst".

Finally, it is important to note that the categories of "containment" and "collaboration" were established through quantitative research. Their use for qualitative research is therefore debatable. However, there is a significant lack of qualitative research that directly investigates media responses to populism. More precisely, there is a lack of discourse analysis in this field. Herrera \& Braumoeller found that content analysis is generally quantitative and uses pre-defined categories, while discourse analysis is most often conducted qualitatively, with a greater emphasis on the role of the researcher (2004, p.17). Neuendorf argues that both discourse and content analysis are important, the former to establish concepts and categories and the later to draw generalised conclusions (2004, p.35). However, in the case of media and populism, there is a lack of discourse analysis. As a result, content analysis, such as

\footnotetext{
$6 \mid$\begin{tabular}{l|l} 
Marble \\
Research
\end{tabular} Papers
} 
that conducted by Deacon and Wright (2016), has proceeded to establish categories instead of discourse analysis. Therefore, I do not simply apply these categories to the newspapers I analyse. Instead, my aim is to investigate how well the newspaper articles fit into these categories. Where necessary, I refine the categories, in order to help them reflect possible media reactions more accurately.

\section{How are the newspaper articles analysed?}

\subsection{Discourse analysis}

As stated, I use discourse analysis, in order to determine if the newspaper articles fit into the categories of "active containment" or "collaboration" and to refine and add categories where they are needed. I chose to conduct discourse analysis over content analysis, as there is a lack of discourse analysis in this field. Many authors have already conducted quantitative content analyses, in order to determine how much and what kind of populism was mentioned in newspapers and if these trends increased or decreased (see Deacon and Wright, 2016, Manucci and Weber, 2017 or Rooduijn, 2014). However, the overall focus on content analysis does not mean that discourse analysis is not as vital. Discourse analysis fundamentally differs from content analysis in that the latter is more concerned with reliability and replicability, while the former is mostly concerned with validity (Neuendorf, 2004, p.34). There are also further differences, for example discourse analysis treats anomalies and absences as evidence, whereas content analysis usually does not consider them to be critical (Hopf, 2004, p.31). This means that the two methods, despite their similarities, produce different results. While content analysis is able to identify patterns in documents, discourse analysis allows the researcher to understand the underlying structures that create these patterns (Laffey \& Weldes, 2004, pp.29-30). Therefore, content analysis should always build upon the conceptual definitions and categories determined by discourse analysis (Neuendorf, 2004, p.35). I believe that quantitative research, while being able to discover certain trends, is unable to determine how newspapers report on a populist party.

In the case of Germany, qualitative research is especially important, as only by conducting an in-depth discourse analysis can we determine whether a newspaper demonstrates "Berührungsangst" or not. Furthermore, qualitative research is needed to discover how newspapers report on populism and what indicators allow us to quickly determine the strategy that a newspaper follows. Conducting this qualitative discourse analysis on a smaller scale might eventually help the larger scale content analysis in this field to go beyond simply answering how often populism is mentioned in newspapers. I want to improve the categories used by quantitative researchers, in order to enable future researchers to analyse the trends that different kinds of newspapers follow in reporting on populism more accurately.

A major difference between content analysis and discourse analysis is that content analysis relies on a strict coding plan, while in discourse analysis "the researcher serves as the measurement instrument" (Neuendorf, 2004, p.34). Therefore, I do not apply a rigid coding scheme to analyse the newspaper articles. Instead, I establish basic indicators, which suggest that a newspaper fits into the category of "containment" or of "collaboration". However, the analysis also takes the circumstances of any given indicator, as well as absences of certain indicators, into account. I also take note if a newspaper shows no, or few indicators that place it in either category, or if it demonstrates indicators of both categories. In these cases, I investigate possible causes and how the categories might be adapted to include this newspaper more accurately. 


\subsection{Attaching indicators to the categories}

Any action by a newspaper that discourages people from voting for the AfD is an indicator of containment. The strongest indicators are articles that directly or indirectly ask people not to vote for the AfD. However, Matheson finds that most of the time, newspapers influence their readers less directly, by using language to impact how their story is perceived by the audience (2005, p.16). He identifies the use of labels as a crucial way of achieving this (p.17). Matheson argues that when a newspaper applies a label to a person or group, it allows society to judge their actions and make generalisations about them (p.24). Therefore, another indicator of containment is the use of negative labels, such as labelling the AfD, or members of the AfD, as racist, nationalist, foreigner haters, extremists or as (Neo-)Nazis. If the newspaper uses quotes by experts, politicians or other people who label the AfD as such, it is also an indicator of containment. However, not each label is an equally strong indicator. For example, articles that refer to the AFD as right-wing populists, or quote people referring to them as such, are only a light indicator of active containment, as the label is not necessarily purely negative. Finally, another light indicator of containment is demonstrated by articles that directly criticise actions taken by the AfD. It is only a light indicator, as criticizing the actions of parties and politicians is something that newspapers commonly do. While it demonstrates that the newspaper disapproves of a certain action or policy by that party, it does not adequately show that they disapprove of the party overall.

Newspapers that show support for ideas of the AfD and encourage people to vote for it belong into the category of "collaboration". Therefore, any articles directly or indirectly asking people to vote for the AfD would be considered as strong indicators for this category. Furthermore, if the newspaper uses rhetoric that is commonly used by populist parties, such as stating that the AfD represents the people and that it fights back against the corrupt elite, or if it labels the party as patriotic, this would also be an indicator of collaboration. The newspaper may also publish articles that support the ideas of the AfD or defend them from its opponents. This would only be considered a weak indicator of collaboration, because support of, or defence for, a certain action or policy does not necessarily indicate support for the party overall. Furthermore, I will be careful not to misinterpret criticism of another party's actions as support of the AfD.

I also try to determine whether the concept of "Berührungsangst" is still relevant in the German media today. Therefore, I will investigate whether I can find examples of it in the newspapers that I analyse. The original idea of "Berührungsangst", that newspapers are unwilling to talk about populism because they are afraid to be associated with National Socialism, is less relevant today, as newspapers in Germany do regularly report on the AfD. However, I believe that Berührungsangst, in various forms and strengths, is still present in newspaper reports on the AfD today. The highest level of "strong Berührungsangst" would be shown by a newspaper which criticises the AfD for being Nazis or Neo-Nazis or which states that they are repeating mistakes from the German past. Labelling and condemning the AfD in this way ensures that the newspaper could not be labelled as a Nazi-paper itself. If the newspaper ignores the topic of National Socialism and its possible connection to populism, this indicates a different form and level of "some Berührungsangst". It indicates that the newspaper may hope that the readers will not connect their reporting on the AfD to National Socialism, if they ignore it themselves. However, this form is less strong, as the newspaper does not feel the need to distance itself actively from the topic, by criticizing the AfD as Nazis. The strongest indicator that a newspaper fits into the category of displaying "no Berühnrungsangst" would be that they openly discuss the topic, including articles that

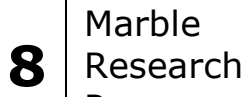
Papers
} 
state that the AfD are not Nazis. This would demonstrate that they have no fear of the topic, as they address it in a way that carries the risk of being accused of defending Nazis.

\subsection{Structuring the analysis}

The analysis of the newspaper articles conducted in this paper is split into two parts. The first compares the similarities between the newspapers. It discusses which newspapers fit into the same category and why they fit into that particular category. It also demonstrates which newspapers used similar strategies to achieve containment or collaboration. The second part analyses the differences between the newspapers. This part focuses on the extent to which each newspaper fits into its category and whether they truly fit into either category at all. While several newspapers are part of the same category, they do not participate in containment or collaboration to the same degree. The more indicators a newspaper fulfils and the stronger these indicators are, the higher the extent to which it fits into a certain category. This section also contrasts letters to the editor and other forms of readers' opinions that are published by the newspapers. These are not used to determine the category of a newspaper, as the opinions of the readers do not necessarily reflect the opinions of the editors and authors of the newspaper. However, it is possible to analyse how willing the newspaper is to publish different opinions and possibly even criticism on their own articles. This helps to determine the extent to which the newspaper fits into a certain category. If they only, or mostly, publish readers' opinions that agree with their articles, they fit into their category to a greater extent. However, when they publish opinions that oppose, or even criticise, their articles, this would harm their goal of either containing or collaborating with the AfD. Therefore this lessens the extent to which they fit into one category. Finally, this part contrasts the level of Berührungsangst that is present in the different newspapers.

\section{Commonalities between the newspapers}

All newspapers that were analysed can be placed into the category of "active containment". One tactic used by all to contain the AfD is to discredit them, by labelling them as racists, extremists and nationalists. Furthermore, they all make use of quotes by experts and politicians who criticise the AfD in some form, in order to discredit them further.

This may suggest that newspapers in Germany are generally very likely to actively contain the AfD. The type of newspaper, whether it was a tabloid, a quality paper, a paper from the East or from the West, or if it was published online or in print, made no difference to its category.

\subsection{The B.Z.}

The clearest case of active containment can be found in the tabloid "B.Z." This newspaper published several articles in which the AFD is criticised and portrayed in a negative light. It achieves this by labelling them as a racist party that creates and exploits resentment and fear in the population (Bz3, Bz7, Bz13, Bz9, Bz25). In another article, they call an AfD member a liar (Bz19). Moreover, several articles quote politicians and experts who criticise the AfD and even compare them to Nazis (Bz5, Bz11, $B z, 15, B z 16, B z 22, B z 23)$. Furthermore, they openly state their own feelings about the AfD, when they recount their reaction to the election results. There are several articles in which the author states that it is "a shame" that the AFD is so successful and that they are "shocked" and concerned about the future 
as a result (Bz4, Bz13, Bz20). However, they are also quite critical of how the politicians of established parties deal with the AfD. One article criticises a politician for stating that it is better not to vote, than to vote for the AfD (Bz1). Another article defends AfD voters from a politician, who stated that they were not welcome in his home (Bz6). Furthermore, they published an article criticizing a politician who did not condemn violence against AfD members (Bz12). Finally, they even criticise the established parties for stealing the good idea of giving medals to senior police officers from the AfD (Bz24). Nevertheless, this is not collaboration, as the "B.Z." overall does not support the ideas and values of the AfD. Most of their less negative articles on the AfD do not defend the party, but criticise established politicians for becoming more like them. A good example is an article that directly accuses an established politician for using rhetoric that "reminds of the rhetoric of the AfD" (Bz21). Moreover, they actively attack the political beliefs of the AfD. For example, they dedicated an article to prove the AfD wrong in claiming that refugees cannot integrate into German society, giving two detailed examples of successful integration (Bz8). In another article, they state that it was the right decision to let so many refugees enter Germany, "despite AfD propaganda" (Bz10). Finally, they even published an article before the election asking people not to vote for the AFD (Bz17). Therefore, this newspaper is very clearly engaged in active containment, as they try to portray the AfD in a negative light and even discourage people from voting for them.

\subsection{The Mitteldeutsche Zeitung}

The "Mitteldeutsche Zeitung" is similarly engaged in active containment. While none of their articles directly ask people not to vote for the AFD, they did publish one article expressing hope that people would not vote for the party (Mi18). They also published another article, arguing that Germany deserves something better than the AfD (Mi30). These statements are clear examples of active containment, as they are meant to discourage people from voting for the AfD. Furthermore, they also try to discredit the AfD in order to contain it. One tactic that they use to achieve this is to label members of the AfD as nationalists, racists and radical extremists (Mi8, Mi9, Mi30). Another article describes the AfD as "false prophets" (Mi17). Similarly to the "B.Z." they also quote statements by experts and politicians expressing shock at the success of the AfD and criticizing the party (Mi4, Mi5, Mi10). This demonstrates that they use several tactics to discredit the AfD. One article did represent the side of the AfD, as it quotes an AfD voter stating that she is no Nazi, and that her vote was not decided by the refugee crisis, but by her everyday life (Mi1). However, this article is an outlier and even it is not particularly positive towards the AfD, but instead should be classified as neutral. Therefore, this article should not be seen as evidence that the "Mitteldeutsche Zeitung" can be classified as collaborating with the AfD.

Indeed, they regularly criticise actions taken by the AfD directly. For example, two of their articles criticise the AfD's push to investigate left-wing extremism, arguing that it would be dangerous not to investigate right-wing extremism, which is three times as common, as well (Mi6, Mi10, Mi11). Another two articles are devoted to criticizing AfD members for disturbing speeches by Merkel in East Germany with loud noises, rather than engaging in a civilized argument (Mi6, Mi27). This demonstrates that criticizing the actions of the AfD is yet another way in which the "Mitteldeutsche Zeitung" tries to actively contain them. 


\subsection{The Aachener Nachrichten}

The "Aachener Nachrichten" is also engaged in active containment, although less vehemently than the previous two newspapers from the East. Similarly to these newspapers one of their main strategies is to discredit the AfD, by associating it with the far right. Their main way of achieving this is by consistently labelling them as (radical) right-wing populists, as nationalists and as racists (Aa13, Aa15, Aa17, Aa20, Aa23, Aa24). They also make use of quotes to an even greater extent than the previous newspapers, quoting experts, politicians, regular people and even religious figures, who criticise the AfD or who report shock on their success (Aa1, Aa5, Aa7, Aa16, Aa26, Aa27, Aa29, Aa30, Aa31, Aa32). However, they do not only report negatively on the AfD. For example, they published a neutral article, summarising the programs of all parties, including that of the AfD (Aa25). They also wrote two other neutral articles on AfD candidates (Aa22, Aa33).

Furthermore, in a report on the attack of the AfD on the "Bündnis gegen Rechts" (Union against the right) the author includes quotes from both the established parties and the AfD (Aa12). They also quote an AfD candidate, who criticises a politician for telling people not to vote, rather than to vote for the AfD (A11). While these reports are neutral towards the AfD or criticise another party, they do not support ideas and actions of the party. Therefore, they do not offer evidence of collaboration. There is one article, in which the author argues that value added tax should be reduced and mentions that the AfD has a plan to do so (Aa6). However, he does not commend them for it, but instead criticises the established parties for having no such plans (Aa6). The closest the "Aachener Nachrichten" comes to collaboration is in an article, where the author criticises journalists for simply portraying the AfD as "bad" (Aa3). However, the author immediately distances himself from the party, by stating that he did not vote for the AfD himself (Aa3). Therefore, it is a criticism of journalism, rather than a defence of the AfD and their ideas and values. The newspaper does have articles that report on the AfD in a neutral fashion or even criticise its opponents for their behaviour. Nevertheless, these articles are neutral and are therefore not a case of collaboration of the newspaper with the AfD. Indeed, there are many more examples of negative reports on the AfD. For example, the "Aachener Nachrichten" published two articles, which report positively on anti-AfD demonstrations (Aa2, Aa4). They also participated very clearly in active containment when they published an article stating the author's hope that by the next elections, people would realize that the AfD was no real alternative (Aa8). While the "Aachener Nachrichten" seems to have made some effort to publish neutral articles on the AfD, they also published many critical articles, which aim to discredit the party and therefore they should also be categorised as an active container.

\section{$7.4 \quad$ BILD.de}

"BILD.de" is the newspaper that comes the closest to leaving the category of "active containment". Most of its articles would most accurately be described as "neutral" and they mostly treat the AfD in the same way as any other party. Even articles that are critical of them sometimes include a quote from an AfD member or voter, representing their side of the story (Bi6, Bi8). That said, they published no articles that would place them in the category of "collaboration". This exemplifies why it is important to conduct a qualitative discourse analysis, as "BILD.de" does not really fit either of the categories previously established by quantitative content analyses. Some of its articles do use similar strategies to the other newspapers. In two articles, the authors connect nationalism, racism and the radical right to the AfD in

$$
\begin{array}{r|r}
\text { Populism and } & \mathbf{1 1} \\
\text { in Gedia } & \mathbf{1}
\end{array}
$$


some way (Bi1, Bi7). Furthermore, "BILD.de" makes use of quotes by experts and politicians, stating that the AfD exploits the population's fear or criticising them in other ways (Bi2, Bi3, Bi4, Bi5, Bi9). These articles have the aim to discredit the AfD. Therefore, "BILD.de" can be placed into the category of "active containment". While it published no articles directly or indirectly challenging people not to vote the AfD and had far fewer articles discrediting the AfD, it was still, to some extent, trying to contain the party by discrediting it. Nonetheless, as will be discussed in the last section in more detail, its position cannot be described completely accurately with the current categories.

\section{Differences between the newspapers}

\subsection{The extent of active containment}

One significant difference between all the newspapers was the extent to which they pursuit containment of the AFD. "BILD.de" was the newspaper that tried to contain the AfD the least. The only strategy of active containment they pursuit was through discrediting the party, by connecting it to racism (Bi1, Bi7). Even then, most of their articles only associate the AfD to racism or criticise them for being nationalist, by using quotes from politicians and experts ( $\mathrm{Bi} 2, \mathrm{Bi} 3, \mathrm{Bi} 4, \mathrm{Bi} 5, \mathrm{Bi} 9)$. While this indicates a degree of active containment, it is not a strong indicator. In most of their articles, the AfD is treated the same way as any other party. This can be seen by two articles that, while being critical of the AfD, also include statements from the AfD, to show their side (Bi1, Bi7). "BILD.de" only pursuits a very low degree of active containment and most of its articles would be better described as neutral towards the party.

The "B.Z." on the other hand shows a very high degree of active containment. Some of their articles demonstrate strong indicators of containment, telling their readers directly not to vote for the AfD (Bz17) or stating that it is "a shame" that they are so successful (Bz20). Another indicator is that they published several articles that aim to discredit the AfD. They use this strategy more aggressively than the other newspapers, as they label the AfD as racists (Bz7, Bz9), liars (Bz19) and even include several quotes calling them, or comparing them to, Nazis (Bz9, Bz11, Bz16). None of the other newspapers use words with such a negative connotation to describe the AfD. Finally, they also directly criticise actions taken by the AfD (Bz8, Bz10). While this is the weakest indicator of active containment, it further adds to the number of strategies that the "B.Z." uses to contain the AfD.

The "Mitteldeutsche Zeitung" and the "Aachener Nachrichten" fall in between "BILD.de" and the "B.Z." in terms of their level of active containment. The "Mitteldeutsche Zeitung" pursuits a similar level of active containment as the "B.Z.". Like the tabloid, they published articles strongly discouraging people from voting the AfD (Mi18, Mi30). Furthermore, they employ the strategy of discrediting the AfD by labelling them as racist, nationalist, and radical extremist (Mi8, Mi9, Mi30). They also quote experts and politicians to portray the AfD as an unwanted development (Mi4, Mi5, Mi10). Moreover, out of all the newspapers, they published the most articles directly criticizing actions by the AfD (Mi6, Mi10, Mi11, Mi27). However, as this is the weakest indicator of active containment, it is not enough to justify elevating them to the same level of active containment as the "B.Z.". The "B.Z." is more aggressive in its discrediting of the AfD, due to describing them as Nazis. Also, unlike the "Mitteldeutsche Zeitung", they published an article directly telling their readers not to vote for the AfD (Bz17). Nonetheless, as they use several tactics to contain the AfD, the "Mitteldeutsche Zeitung" still demonstrates a rather high level of active containment.

\footnotetext{
$12 \mid$\begin{tabular}{l|l} 
Marble \\
Research \\
Papers
\end{tabular}
} 
The "Aachener Nachrichten" fits into the category of active containment to a lesser extent, although it does show a higher level of it than "BILD.de". Their article showing the strongest indicator of active containment is one expressing hope that less people would vote the AfD by the time of the next elections (Aa8). Furthermore, they use the tactic of discrediting the AfD by calling them racists, nationalists and radicals ( $\mathrm{Aa13}, \mathrm{Aa15}, \mathrm{Aa17}, \mathrm{Aa20}, \mathrm{Aa23}, \mathrm{Aa24}$ ) and by quoting different people criticising the party (Aa1, Aa5, Aa7, Aa16, Aa26, Aa27, Aa29, Aa30, Aa31, Aa32). Indeed, they published more articles employing this strategy than any of the other newspapers. However, they also published the most articles on the AfD overall. Furthermore, they did not publish any articles before the election directly or indirectly asking people not to vote for the AfD. They also did not criticise any action taken by the AfD directly. While this is the weakest indicator of active containment, it is another strategy that is employed by both the "Mitteldeutsche Zeitung" and the "B.Z.", but not the "Aachener Nachrichten". Finally, while the "Aachener Nachrichten" may have published the most articles discrediting the AfD in some way, these articles pursuit this strategy far less aggressively than for example those of the "B.Z.". Thus, while there are clear indicators of active containment in the articles of the "Aachener Nachrichten", they fit into this category to a lesser extent than the two newspapers from Eastern Germany.

\subsection{Readers' opinions}

Another interesting difference between all of the newspapers is how they publish the opinions of their readers on their articles about the AfD. "BILD.de" did not publish any of the opinions of its readers, possibly because it is an online newspaper. Perhaps it is also due to the nature of tabloids, as the "B.Z." published only a single letter to the editor. In this letter, the reader compares the rejection of AfD voters by a politician to Jews not having been welcome in Nazi Germany (Bz14). The original article by the "B.Z." had also criticised this politician (Bz6). It is certainly interesting that the only opinion of a reader that was published by the "B.Z." seems to defend the AfD. However, it has to be kept in mind that the reader agreed with the original article and that criticizing a politician for his treatment of the AfD is not the same as defending the AfD or expressing support for it. Nevertheless, it is clear that the "B.Z." did not selectively publish readers' opinions that would aid in the containment of the AfD.

The two quality newspapers published a lot more readers' opinions of their articles on the AfD. The "Mitteldeutsche Zeitung" published many opinions that label the AfD as right-wing, nationalist, racist, dangerous or express shock and regret at the success of the party (Mi2, Mi3, Mi12, Mi13, Mi14, Mi20, Mi24, Mi29). Only one opinion expresses support for the AfD, whishing them "luck against the established parties" (Mi21). This seems to suggest that they deliberately chose to publish significantly more opinions that discredit the AfD in some way. However, they also published many opinions that are neutral towards the AfD and call on established politicians to learn from the elections (Mi12, Mi15, Mi28, Mi29). There are also a couple of opinions defending certain actions of the AfD (Mi3, Mi12, Mi19). Finally, the "Mitteldeutsche Zeitung" chose to publish some opinions that defend the disturbances caused by AfD members at Merkel's speeches in East Germany (Mi16, Mi22), which directly opposes one of their articles, which had criticised the AfD for doing this (Mi6). Therefore, while the "Mitteldeutsche Zeitung" appears somewhat biased in the opinions that they publish, they do also publish opinions that oppose the active containment of the AfD. Moreover, it has to be remembered that the readers of the "Mitteldeutsche Zeitung" are not necessarily representative of the Eastern German population. 
Therefore, they might simply have more opinions that criticise the AfD that they can publish than ones that defend or support them.

Finally, the "Aachener Nachrichten" also published several readers' opinions that criticise the AfD (Aa9, Aa18, Aa21). They only published one opinion expressing satisfaction at the success of the AfD (Aa9). However, they also published two more opinions defending the AfD and criticizing the media and even the "Aachener Nachrichten" directly for not reporting fairly on the party (Aa21, Aa28). Overall, they seem to be the most open for criticism, as they themselves published an article criticizing journalism for portraying the AfD as simply "bad" (Aa3), while also publishing a letter to the editor, in which the reader criticises the news for focusing too much on topics that are beneficial to the AfD (Aa10). Finally, they published two opinions that blame the established parties for the success of the AfD (Aa19). While these opinion pieces mainly criticised the established politicians, calling the success of the AfD their "fault", they, by doing so, also portray the success of the AfD as something negative. Overall, the "Aachener Nachrichten" published more opinions that discredit the AfD than ones that support or defend it. Nevertheless, it is quite possible that they received more opinions that discredit the AfD, as in the West, the AfD was significantly less successful than in the East. Considering how many opinions do defend or even express support for the AfD, it is possible that the "Aachener Nachrichten" made a conscious effort to publish opinions from both sides. Furthermore, they are the newspaper that published by far the most critical opinions on journalism and on themselves.

\subsection{Berührungsangst}

"Berührungsangst" is present in most of the newspapers to some extent. The clearest case of it can be seen in the "B.Z.". It actively labels the AfD as Nazis or Neo-Nazis. In one article on the AfD, the author reminds people that there was always a danger that something like Nazi Germany could occur again and implies that it is now more likely than ever before (Bz9). Another article reports on an alleged "Nazimail" written by an AfD candidate (Bz11). Furthermore, they report a Jewish person being worried about the success of the AfD (Bz2). They also quote several people calling AfD members Nazis. A theatre owner and a protestor are quoted, stating that while not all AfD members are Nazis, some certainly are (Bz18, Bz24). A politician is quoted calling the AfD "history revisionists and Nazis" (Bz16). Finally, they quote an expert stating that he finds the success of the AfD dangerous, because the Nazis came into power in the same way (Bz15). They certainly present the AfD, or at least members of it, as Nazis. While this demonstrates that they have no fear of talking about the topic, they certainly do seem to fear that they could be accused of denying a relation between Nazis and the AfD. The article that comes closest to doing so states that the AfD is not "a result of the Nazi-past" (Bz7). However, even this article does not directly state that there are no Nazis in the AfD, but only that they did not evolve as a result of Germany's past. Overall, there are many articles that directly or indirectly accuse the AfD of being Nazis, with perhaps one disagreeing with this accusation. Therefore, it appears that the "B.Z." is doing its best not to be accused of defending or denying that the AfD has connections to Nazis, demonstrating a high level of "Berührungsangst".

The "Mitteldeutsche Zeitung" shows less conviction that the AfD are Nazis. They did publish an article stating that some members of the party are Nazis (Mi8) and another quoting a politician saying that an AfD speech reminded him of a Neo-Nazi convention (Mi10). Furthermore, they published an article on how the AfD receives support from radical Americans, arguing that the line between being right-wing populist, new fascist and Nazi is not clear cut (Mi25). However, they also published an article

\footnotetext{
Marble

14 Research

Papers
} 
quoting an AfD voter on being "no Nazi" (Mi1). Moreover, when they published an article on the same alleged "Nazi-mail", covered by the "B.Z." (Bz11), they chose to call it a "mail containing radical ideas" (Mi30). This shows that when possible, they try to avoid the topic of National Socialism, which could hint at a different form of "Berührungsangst". They certainly do cover the topic less than the "B.Z.". When they are forced to, or choose to, address the topic, they are slightly more balanced in their portrayal of it, but overall, they still mostly accuse and criticise the AfD of being Nazis. Thus, they show at least a moderate level of "Berührungsangst".

The "Aachener Nachrichten" covers the topic even less than the previous newspaper. They also present the topic in a more balanced way than the newspapers from the East. In one article, they quote a Jewish person stating that he is worried that the AfD may develop anti-Semitic tendencies in the future (Aa14). This article comes the closest to accusing them of being Nazis, but only implies that there is a danger that they might become Nazis. Another article quotes a different person stating that the AfD is "no Nazi-party" (Aa30). This demonstrates that the "Aachener Nachrichten" covers views from both positions. However, most articles do not mention the topic at all. One article states that the AfD is not necessarily radical (Aa17). This shows how the "Aachener Nachrichten" tries to avoid using the word "Nazi". Indeed, the only time they use it is in a quote from somebody that does not work with them. This avoidance of the topic suggests that they have a form of "Berührungsangst". As they seem to believe that the AfD is no Nazi party, they possibly avoid the topic in order to prevent being accused of denying it or defending the AfD. Therefore, they also show some level of "Berührungsangst".

Finally, "BILD.de" only mentions the topic in a single article, stating that the AfD is no Nazi party (Bi9). This lack of writing on the topic could again demonstrate "Berührungsangst" with the topic. However, it has to be remembered that the number of articles that "BILD.de" wrote on the AfD is far lower than those of the other newspapers. Therefore, while they only wrote one article on the topic, this does not mean that the percentage of their articles that is dedicated to this topic is lower than that of the "Mitteldeutsche Zeitung". Furthermore, unlike the "Aachener Nachrichten", they do not use other people to state that the AfD is no Nazi party. Moreover, they published no article that would in any way suggest that the AfD is a Nazi party. Therefore, they seem to be rather confident in their position on the topic. Possibly, "BILD.de" is experiencing no, or a very low level of "Berührungsangst". However, it is also possible that they do, as the number of articles published on the topic is not very high at all. Overall, all newspapers experience "Berühnrungsangst" to some extent and in some form, with the possible exception of "BILD.de".

\section{The importance of qualitative discourse analysis in challenging predictions and improving the established categories}

Contrary to what would generally be expected by most of the established literature, the tabloids did not collaborate with the AfD and the Eastern newspapers were no less critical of it. Instead, the tabloids were both acting in the category of "active containment" and even on opposite sides of the spectrum within this category. Furthermore, the Eastern newspapers were more critical of the AfD than the Western ones, showing more and stronger indicators of active containment and pursuing several strategies aggressively in order to achieve containment. While these findings challenge the established predictions and theories, they do not disprove them. Nevertheless, they do demonstrate the necessity of 
more in-depth, qualitative discourse analysis in this area, in order to discover not only the surface level trends, but also the underlying connections and causes. Even if this case is simply an outlier, more research is needed to discover whether this is the case and to answer why these specific newspapers deviate from the common expectations.

This research also discovered that newspapers within the category of "active containment" can range from an almost neutral position, where only a small amount of articles show signs of active containment, to a very strong position of active containment, where almost every article demonstrates indicators or strong indicators of containment. Therefore, I propose to add a "neutral" position that newspapers can occupy to the already established categories of "passive containment", "active containment", "collaboration" and "competition". Newspapers, such as "BILD.de" would arguably fit better into such a category, as it mostly reports on the AfD in the same way as on other parties. Other newspapers may fit this category even better. Furthermore, the establishment of a detailed scale, ranging from a neutral position to one of strong containment, would enable us to describe the position of a newspaper more accurately. After all, each of the newspapers demonstrated a different degree of active containment. Further research into such a scale may investigate what signs and indicators correlate to each specific rating on the scale. This would allow us to accurately and consistently describe and analyse the positions of newspapers towards populist parties.

\section{Conclusion}

Most academic literature on the relationship between newspapers and populism has focused on quantitative research that investigates how often populism is mentioned by the newspapers. However, in this paper I conducted a qualitative discourse analysis in order to investigate how newspapers report on the AfD in Germany. The results contradict the established theory, which predicts that tabloids are more likely to collaborate with the populist party, while quality newspapers were more likely to fit into the category of "active containment". However, this research discovered that all newspapers took a stance of active containment towards the AfD, with the tabloid "BILD.de" pursuing it the least aggressively and the tabloid "B.Z." pursuing it the most aggressively. They also differed in how they published readers' opinions. "BILD.de" published no opinions and the "B.Z." only published one. The "Mitteldeutsche Zeitung" published many opinions, most of them agreeing with their articles and their stance towards the AfD. The "Aachener Nachrichten" also published many opinions and published the most critical opinions of all the newspapers. Finally, the strength of active containment correlated with the strength of "Berührungsangst" that the newspapers were showing. The "B.Z." showed strong signs of "Berührungsangst", criticizing the AfD regularly as Nazis, while the "Mitteldeutsche Zeitung" took a similar, though somewhat more nuanced stance. The "Aachener Zeitung", which pursuit active containment less vehemently, only showed some "Berührungsangst" as they mostly avoiding to address the topic. Finally, "BILD.de" showed a similar reluctance to write about the topic, although they did publish one article stating that the AfD was no Nazi party. This could suggest that they are somewhat more comfortable with the topic, as they addressed it in a possibly controversial way by defending the AfD.

It is certainly interesting that the newspapers in the East, where the AfD is more successful, were more critical of the party. One could speculate that this is because they are afraid of the success of the AfD in their region and therefore want to contain the AfD more actively. It is possible that this only

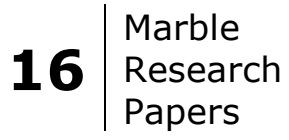


further encourages and strengthens the AfD as a protest party. After all, one of the main ideas of populism is that of fighting the corrupt elite. When newspapers, which populists usually consider being part of the elite, attack them and treat them differently than other parties, this may strengthen their resolve and support their claim to fight the corrupt elite. However, further research in this area is essential, in order to demonstrate if these ideas have some validity to them, or if they are simply speculation. As only four newspapers could be analysed within the scope of this paper, it is unable to represent all German newspapers, much less newspapers worldwide. The time period focused on is also quite short, only spanning two months. I am therefore unable to draw any significant conclusions on the trends that these newspapers show or how they develop over time. Nevertheless, this is not the aim of discourse analysis, as generalizations can only be made by conducting further quantitative content analysis. While this research can draw no definite conclusions on trends, it does demonstrate the importance of qualitative discourse analysis in this field. Only by conducting this kind of research can we discover where and how more content analyses need to be conducted in the future. Furthermore, more qualitative research needs to be conducted, in order to determine the underlying causes and relationships that determine how newspapers react to populism and why. In order to improve upon the categories established by previous, quantitative research, I propose that a "neutral" position should be added to describe the position of newspapers towards populist parties. This would enable us to better categorize papers, such as "BILD.de". Finally, I suggest that further research should develop a detailed scale that ranges from this "neutral" position to one of "strong active containment" and to have clear indicators associated with each rating on this scale. 